\title{
Successful endoscopic diagnosis and treatment of blue rubber bleb nevus syndrome
}

A young man presented with a two-year history of recurrent melena. Several dark-blue elevated skin lesions had been on his right hand and head ( $\mathbf{F i g}$. 1). The nodules were soft and compressible, and some of them seemed to have lacunae divided by white linear structures. Pathologic examination after a surgical resection two years ago confirmed the lesions as "cavernous hemangioma." No one in his immediate family had a related vascular malformation. His hemoglobin level was $56 \mathrm{~g} / \mathrm{L}$ (severe anemia), and the other related tests and physical examinations were unremarkable.

Images of magnetically controlled capsule gastroscopy also showed multiple congested, nodular lesions in the esophagus ( $\triangleright$ Fig.2) and small intestine ( Fig.3), and ultrasound endoscopy showed a gastric submucosal eminence lesion caused by compression from a swollen spleen. Some bleeding lesions were also recorded by magnetically controlled capsule gastroscopy ( $\mathbf{F i g . 4 ) .}$

Other congenital vascular malformation syndromes were excluded and the diagnosis of blue rubber bleb nevus syndrome was adopted. The patient was treated with supportive care and blood transfusions for severe anemia. Endoscopic sclerotherapy (polidocanol injection) for esophageal and small intestinal varices was conducted to prevent gastrointestinal rebleeding ( $>$ Fig. 5 , \ Video $\mathbf{1}$ ). During the subsequent follow-up for half a year, he never manifested anemia again. Blue rubber bleb nevus syndrome is a rare syndrome of multiple venous malformations of the gastrointestinal tract, skin, and other visceral organs [1]. Multiple blue to violaceous soft compressible nodules on the skin or mucous membranes usually present in early childhood. Moreover, patients are at increased risk for gastrointestinal hemorrhage and severe iron deficiency anemia.

Nowadays, various endoscopic treatments including sclerotherapy, band liga-

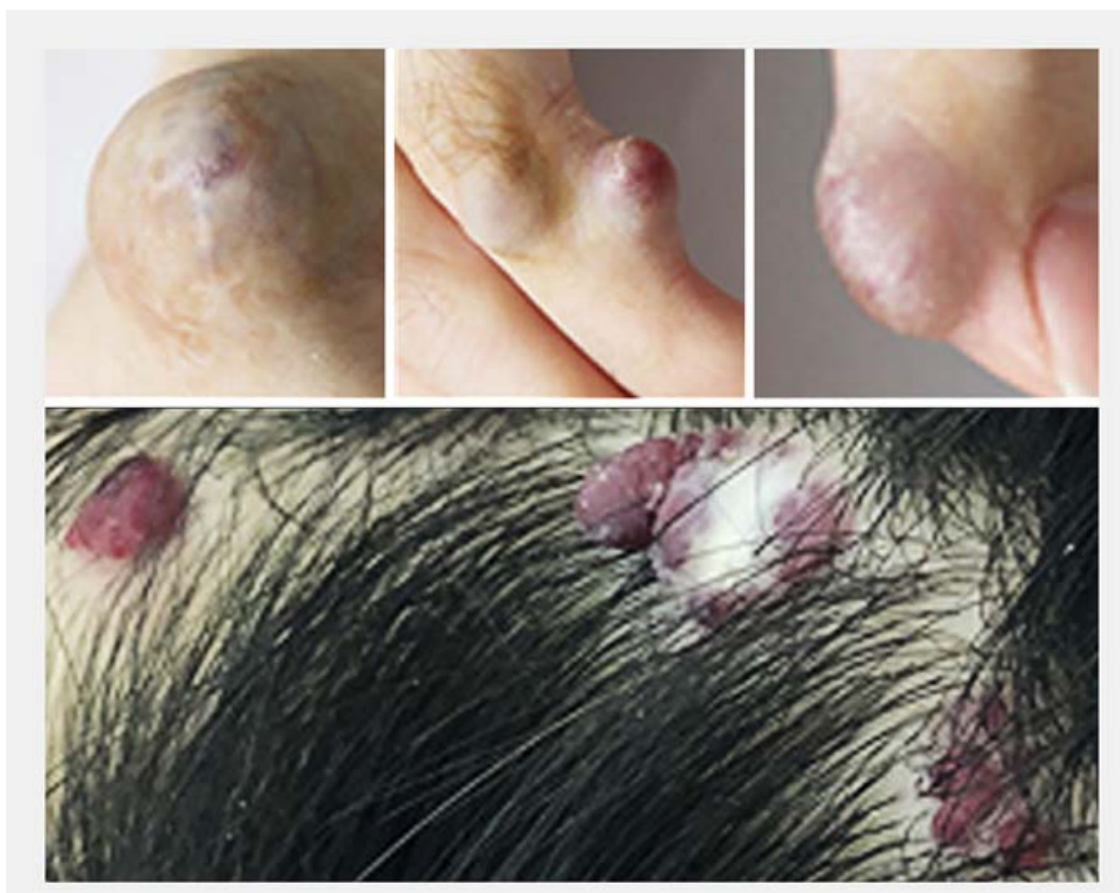

Fig. 1 Dark-blue elevated skin lesions presented on the patient's right hand and head.

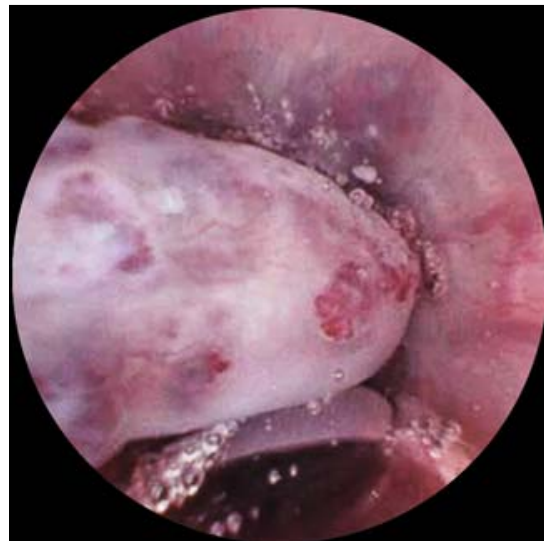

- Fig. 2 Multiple congested, nodular lesions in the esophagus recorded by magnetically controlled capsule gastroscopy.

tion, or laser photocoagulation have been suggested for gastrointestinal lesions. Children and adolescents may benefit from the simple and relatively non-invasive interventions. Surgical operations

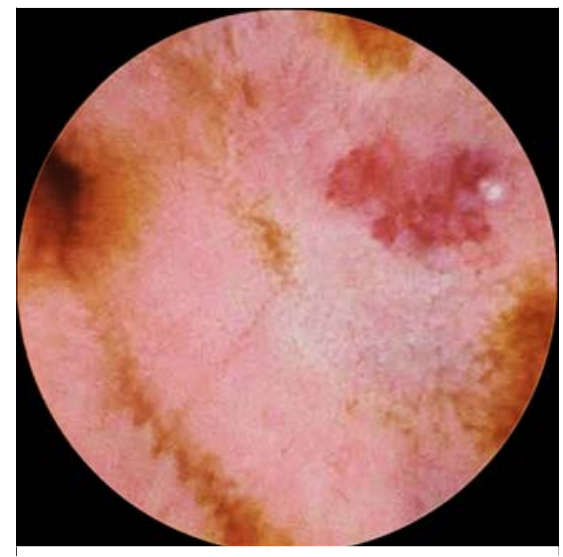

Fig. 3 Several lesions in the small intestine recorded by magnetically controlled capsule gastroscopy.

may be necessary if the gastrointestinal hemorrhage is life-threatening [2].

Endoscopy_UCTN_Code_CCL_1AC_2AB 


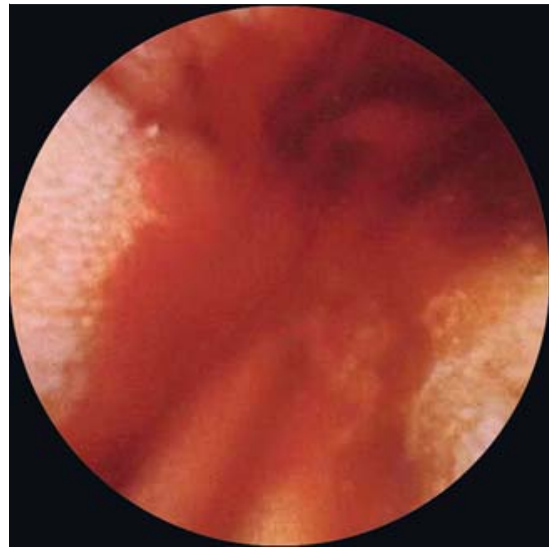

- Fig. 4 Bleeding lesions recorded by magnetically controlled capsule gastroscopy.

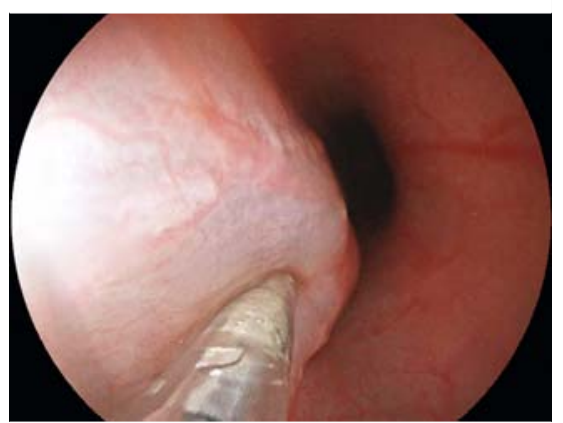

- Fig. 5 Endoscopic sclerotherapy (polidocanol injection) for small intestinal varices.

\section{Competing interests}

The authors declare that they have no conflict of interest.

The authors

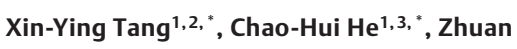
Liao $^{1,4}$

1 Department of Gastroenterology, Changhai Hospital, Second Military Medical University, Shanghai, China

2 Department of Prevention and Health Care, Eastern Hepatobiliary Surgery Hospital,

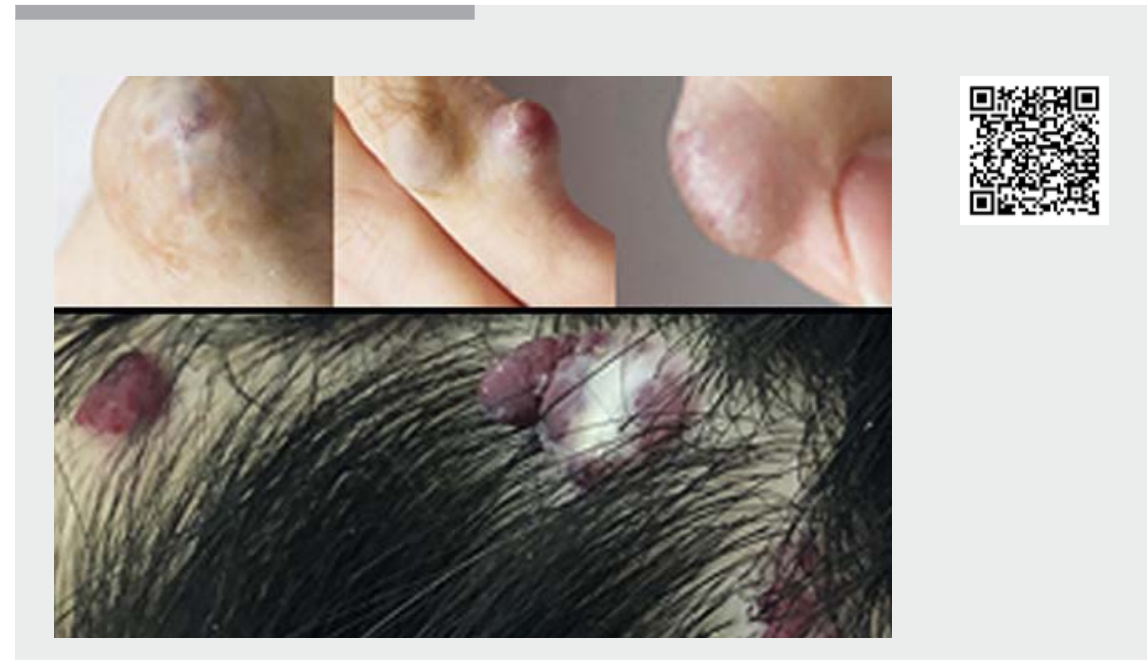

Video 1 Successful endoscopic diagnosis and treatment of blue rubber bleb nevus syndrome.

Second Military Medical University, Shanghai, China

3 Department of Gastroenterology, Fifth Affiliated Hospital of Zunyi Medical College, Zhuhai, Guangdong, China

4 Shanghai Institute of Pancreatic Diseases, Shanghai, China

\section{Corresponding author}

\section{Prof. Zhuan Liao}

Department of Gastroenterology, Changhai Hospital, Second Military Medical University, Shanghai Institute of Pancreatic Diseases, 168 Changhai Road, Shanghai 200433, China Fax: +86-021-65492727 zhuanleo@126.com

\section{References}

[1] Jin XL, Wang ZH, Xiao XB. Blue rubber bleb nevus syndrome: a case report and literature review. World J Gastroenterol 2014; 20: 17254-17259

[2] Arena M, Virdis M, Morandi E. Blue rubber bleb nevus syndrome: combined surgical and endoscopic treatment. Endoscopy 2015; 47: E372-E373
Bibliography

Endoscopy 2021; 53: E118-E119

DOI 10.1055/a-1202-0716

ISSN 0013-726X

published online 24.7.2020

(c) 2020. Thieme. All rights reserved.

Georg Thieme Verlag KG, Rüdigerstraße 14,

70469 Stuttgart, Germany

\section{ENDOSCOPY E-VIDEOS}

https:/|eref.thieme.de/e-videos

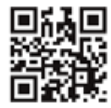

Endoscopy E-Videos is a free access online section, reporting on interesting cases and new techniques in gastroenterological endoscopy. All papers include a high quality video and all contributions are freely accessible online.

This section has its own submission website at

https://mc.manuscriptcentral.com/e-videos
${ }^{*} \mathrm{X}-\mathrm{Y}$ Tang and C-H He contributed equally to this work. 